\title{
Formação docente e inclusão na educação básica: movimentando narrativas de professores/as de Geografia
}

Luiz Martins Junior ${ }^{1}$

Rosa Elisabete Militz Wypyczynski Martins ${ }^{2}$

Suelen Santos Mauricio ${ }^{3}$

\section{Resumo}

O presente texto consiste em analisar as manifestações e percepções por meio das narrativas dos/as professores/as de Geografia sobre os saberes e fazeres da docência com estudantes com deficiência no espaço escolar. Para levantamento dos dados, optou-se pela metodologia qualitativa, de caráter exploratório, envolvendo trinta e quatro professores/as da Educação Básica da cidade de Florianópolis/SC em 2019. Dentre os resultados, constatou-se que os/as professores/as manifestam que lacunas e fragilidades na formação inicial no que toca a essa temática, contribuíram para fragilizar as ações em sala de aula com os/as estudantes com deficiência. Também destacaram a importância da formação continuada em serviço para qualificar as práticas pedagógicas e promover a inclusão escolar. Palavras-chave: Educação Inclusiva; Formação Inicial de Professores; Inclusão Escolar; Ensino de Geografia.

\section{Teacher education and inclusion in basic education: moving narrative teachers of Geography}

\begin{abstract}
This text consists of analyzing how manifestations and perceptions through the narratives of / as teachers / as Geography about sabers and teaching with students with difficulties in the school space. For data collection, we chose the qualitative methodology, of exploratory character, involving thirty-four teachers of Basic Education in the city of Florianópolis / SC in 2019. Among the results, it was found that the teachers manifest that gaps and weaknesses in the initial training with regard to this theme, contributed to weaken the actions in the classroom with students with disabilities. They also highlighted the importance of continuing education in service to qualify pedagogical practices and promote school inclusion.

Keywords: Inclusive Education; Initial Teacher Training; School Inclusion; Geography Teaching.
\end{abstract}

\section{Considerações iniciais}

A formação de professores/as de Geografia e a questão da inclusão dos/as estudantes com deficiência, são temáticas abordadas e problematizadas neste artigo e resultam das discussões e estudos que são impulsionadas através das pesquisas realizadas no Grupo de Pesquisa ${ }^{4}$ (CNPQ), no Laboratório de Estudos e Pesquisa de Educação em Geografia - LEPEGEO, do Centro de Ciência

\footnotetext{
${ }^{1}$ Universidade do Estado de Santa Catarina - UDESC, Florianópolis/SC, luizmartins.jr@hotmail.com

2 Universidade do Estado de Santa Catarina - UDESC, Florianópolis/SC, rosamilitzgeo@gmail.com

${ }^{3}$ Universidade do Estado de Santa Catarina - UDESC, Florianópolis/SC, suelensmauricio@hotmail.com

${ }^{4}$ Ensino de Geografia e diferentes linguagens.
} 
Humanas e da Educação da Universidade do Estado de Santa Catarina - FAED/UDESC. A ideia central deste artigo é analisar as narrativas dos/das professores/as que trabalham com estudantes com deficiência inseridos na Educação Básica. Objetivamos, portanto, chamar atenção para os dilemas e desafios enfrentados pelos professores/as de Geografia no seu fazer pedagógico quando tem em sala de aula estudantes com deficiência.

A opção pela metodologia exploratória ancorada na abordagem qualitativa teve como propósito explorar e compreender a materialidade das percepções dos professores/as de Geografia a respeito da inclusão dos/das estudantes com deficiência no cotidiano escolar. Os dados foram gerados a partir de um questionário com questões abertas e fechadas que se destinaram a professores/as de Geografia que atuam na rede pública e privada de ensino de Florianópolis/SC, no primeiro semestre de 2019.

Considerando a realidade da formação de professores de Geografia e a inclusão da pessoa com deficiência, é importante destacar o direito a aprendizagem destes estudantes. Os imperativos legais, as ações governamentais, a formação inicial e continuada são elementos que se entrecruzam nesse cotidiano e que reverberam no percurso formativo tanto dos professores/as quanto dos/das estudantes.

As políticas de inclusão no território brasileiro, amparadas em documentos internacionais, como por exemplo, a declaração de Salamanca de 1994, Convenção Interamericana para a Eliminação de Todas as Formas de Discriminação contra Pessoas Portadoras de Deficiência de 1999, Fórum Consultivo Internacional: Educação para Todos de Dakar de 2000 e a Convenção sobre direitos da Pessoa com Deficiência de 2007, de certo modo, têm avançado significativamente no que toca à defesa do direito e da matrícula do/da estudante com deficiência em todos os níveis e modalidades de ensino, como um princípio único e fundamental de que todas as crianças e jovens tenham o direito a uma educação de qualidade e que possam aprender com as demais, salvo suas singularidades, particularidades, dificuldades e diferenças. É nesse contexto que emergem as várias legislações que contemplam a Educação Inclusiva no país, desde as diretrizes da política nacional de educação especial, criada em 1994, até a criação da nova lei de inclusão, Lei no 13.146 de 06 de julho de 2015, que dispõe sobre as novas diretrizes voltadas para a inclusão (direitos e deveres) da pessoa com deficiência em todos os setores da sociedade. 
Imbuídos de trazer ao debate a formação de professores de Geografia e a inclusão do estudante com deficiência, este texto está organizado da seguinte forma: em um primeiro momento, o desenho metodológico, destacando o contexto da pesquisa e o perfil dos/das professores/as participantes. Em seguida, no intuito de situar o leitor sobre o que os professores/as sabem e pensam sobre a inclusão no espaço escolar, apresentamos as narrativas dos/das professores/as de Geografia acerca da inclusão do estudante com deficiência, o que possibilita identificar alguns dilemas, desafios e as limitações que vivenciam. Finalizando, apresentamos algumas considerações, chamando atenção para a Educação Inclusiva como ação permanente no contexto escolar.

\section{A pesquisa: contexto e metodologia}

Esta investigação ancora-se na abordagem qualitativa de caráter exploratório. Referendada num estudo bibliográfico, realiza análise de conteúdo das narrativas dos/das professores/as de Geografia acerca da inclusão das pessoas com deficiência no processo de escolarização. Sendo assim, debruça-se sobre as espacialidades, os fenômenos, as práticas e as dificuldades que os/as professores/as de Geografia vivenciam e enfrentam no cotidiano escolar, sobretudo no processo de ensino e aprendizagem com estudantes com deficiência.

Segundo Gonçalves (2007) a potencialidade desse movimento investigativo está no fato de que podemos identificar os saberes e dizeres dos participantes da pesquisa, ao ponto de compreender mais de perto o seu contexto, o que também permite conhecer os acontecimentos, as dimensões e as implicações que são tecidas e tramadas, neste caso, no que toca ao que os professores de Geografia pensam e fazem acerca da inclusão dos estudantes com deficiência. Com isso, a contribuição desta pesquisa está estritamente ligada à reflexão em torno dos saberes, desafios, posicionamentos e dificuldades que os/as professores/as de Geografia enfrentam no seu cotidiano escolar ao lidar com estudantes que apresentam algum tipo de deficiência.

A principal fonte de coleta de dados foi a aplicação de um questionário composto por onze questões, sendo seis abertas e cinco fechadas, que forneceram dados relativos à questão dos saberes e dizeres dos/as professores/as que lecionam para estudantes com deficiência. Foi 
enviado o questionário por meio da ferramenta google forms, no primeiro semestre de 2019 para sessenta professores/as de Geografia que atuam na Educação Básica de Florianópolis-SC. Para compreender a opinião e os saberes e dizeres acerca do contexto da inclusão dos estudantes com deficiência no ambiente escolar, entendemos que duas ideias iniciais foram importantes ser priorizadas no corpus do questionário: a primeira, com questões de natureza identitária, considerando as características dos participantes e sua trajetória na Educação e, a segunda, de natureza contextual, com direcionamento de questões que enfatizaram a análise do protagonismo da docência com estudantes que apresentam alguma deficiência, considerando os desafios, limites e as possibilidades no processo de ensino e aprendizagem de Geografia.

Dos sessenta professores que foram enviados os questionários, somente trinta e quatro professores/as responderam, sendo que da totalidade dos participantes respondentes, onze se autodeclararam do sexo masculino e vinte e três do sexo feminino, com idade entre vinte e cinco a cinquenta e cinco anos. Para leitura e análise das falas dos/das professores/as, utilizamos excertos dos depoimentos dos profissionais nomeados por letras do alfabeto A, B, C, D, com vista de preservar a identidade destes sujeitos. Com a intenção de compreender o exercício profissional dos pesquisados, perguntamos: Quanto tempo você possui de atuação no Magistério? Baseado no Gráfico 1, podemos observar que a trajetória profissional dos/das professores/as de Geografia no magistério é considerada significativa, pois somando $28 \%$ dos profissionais que possuem mais de vinte anos na docência com $25 \%$ de professores que lecionam entre 10 e 20 anos é igual a 53\%, conforme se lê no gráfico a seguir, que expressa o tempo de serviço na Educação Básica. 
Gráfico 1. Tempo de serviço

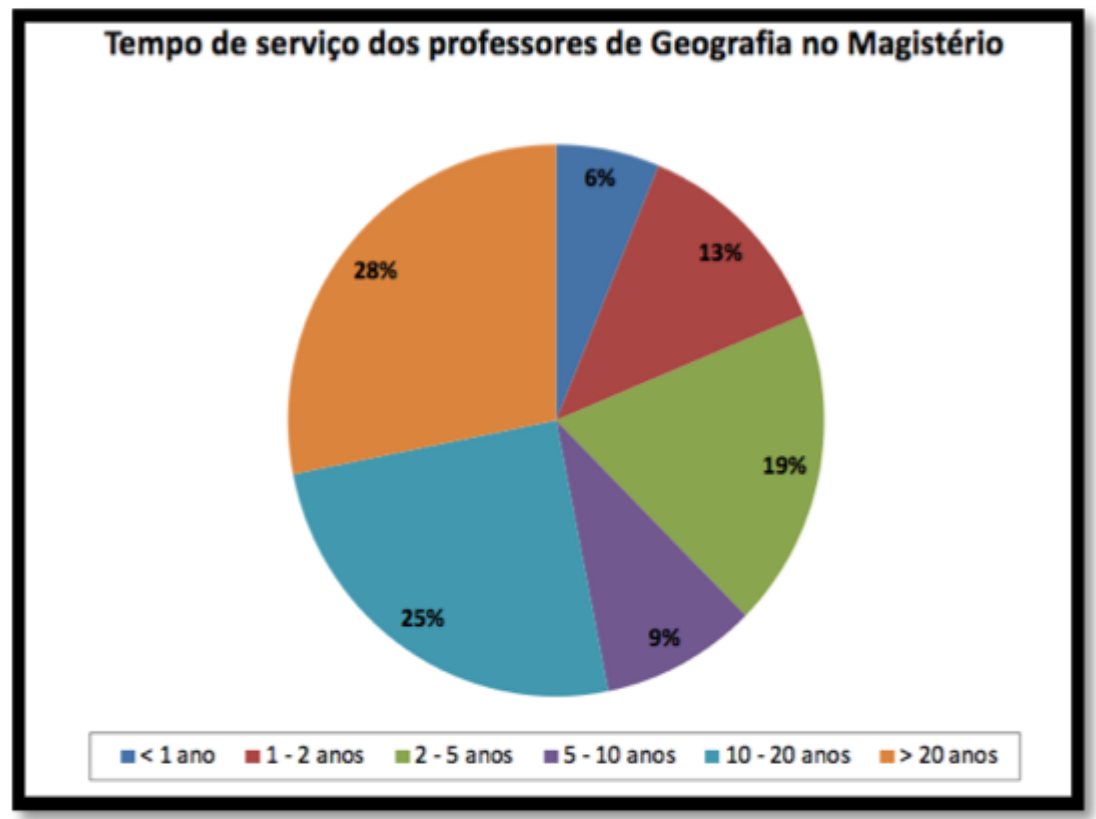

Fonte: autores, 2019.

Conforme pode ser visualizado no quadro acima, apesar da maioria dos/das professores/as terem como lugar de formação inicial uma instituição pública $(66,7 \%)$, há uma menor parcela desses docentes que frequentaram uma instituição privada na graduação em Geografia (33,3\%). Dentre os trinta e quatro participantes, vinte e um, o que representa $56,5 \%$ do total, têm formação em nível de Pós-Graduação na área do Ensino de Geografia, 5\%, equivalente a treze professores/as, não possuem nenhum tipo de especialização na área da Educação ou do Ensino de Geografia. Na perspectiva de mapear o perfil profissional dos participantes, questionamos: Você cursou a graduação numa instituição pública ou privada? Você possui pós-graduação ou está cursando? Você trabalha numa escola pública ou privada? O seu cargo na Educação é efetivo ou contratado5?

Quadro 1. Caracterização do perfil formativo dos professores/as de Geografia

\begin{tabular}{|c|c|c|c|c|c|c|c|}
\hline \multicolumn{8}{|c|}{ PROFESSORES/AS DE GEOGRAFIA } \\
\hline \multirow{2}{*}{$\begin{array}{c}\text { FORMAÇÃO } \\
\text { INICIAL- IES } \\
\text { PÚBLICA }\end{array}$} & \multirow{2}{*}{$\begin{array}{c}\text { FORMAÇÃO } \\
\text { INICIAL- IES } \\
\text { PRIVADA }\end{array}$} & \multirow{2}{*}{$\begin{array}{c}\text { COM PÓS- } \\
\text { GRADUAÇÃOO }\end{array}$} & \multirow{2}{*}{$\begin{array}{c}\text { SEM PÓS- } \\
\text { GRADUAÇÃO }\end{array}$} & \multicolumn{4}{|c|}{ EXERCICIO PROFISSIONAL } \\
\hline & & & & $\begin{array}{c}\text { Professor/a } \\
\text { em escola } \\
\text { Pública }\end{array}$ & $\begin{array}{c}\text { Professor/a } \\
\text { em escola } \\
\text { Privada }\end{array}$ & $\begin{array}{c}\text { Professor/a } \\
\text { Efetivo }\end{array}$ & $\begin{array}{l}\text { Professor/a } \\
\text { temporário }\end{array}$ \\
\hline 33,3 \%: 11 & $66,7 \%: 23$ & $56,5 \%: 21$ & $42,5 \%: 13$ & $93 \%: 28$ & $7 \%: 6$ & $55,5 \%: 20$ & $45,5: 14$ \\
\hline
\end{tabular}

Fonte autores, 2019.

\footnotetext{
${ }^{5}$ Professor/a efetivo/a é aquele que teve sua admissão por meio de concurso público. Professor/a contratado é o que teve sua admissão por meio de processo seletivo e tem um contrato temporário.
}

Periódico Horizontes - USF - Itatiba, SP - Brasil - e020026 
De acordo com a leitura, constatamos que há predominância de professores/as de Geografia que atuam na rede de ensino pública $(66,7 \%)$ em relação a uma menor porcentagem de professores/as que lecionam na rede privada (7\%). Destaca-se, no grupo pesquisado, a maioria dos/as professores/as, de escolas públicas, exercer o trabalho profissional na condição de professor/a efetivo/a, o que registra 55,5\% em relação aos $45,5 \%$ dos professores/as contratados/as.

Os dados relacionados à formação dos professores/as de Geografia nos permitem, em seguida, associar às informações relacionadas no gráfico 2. o ano em que os docentes finalizaram o curso de licenciatura em Geografia.

Gráfico 2. Ano em que o/a professor/a finalizou o curso de Geografia

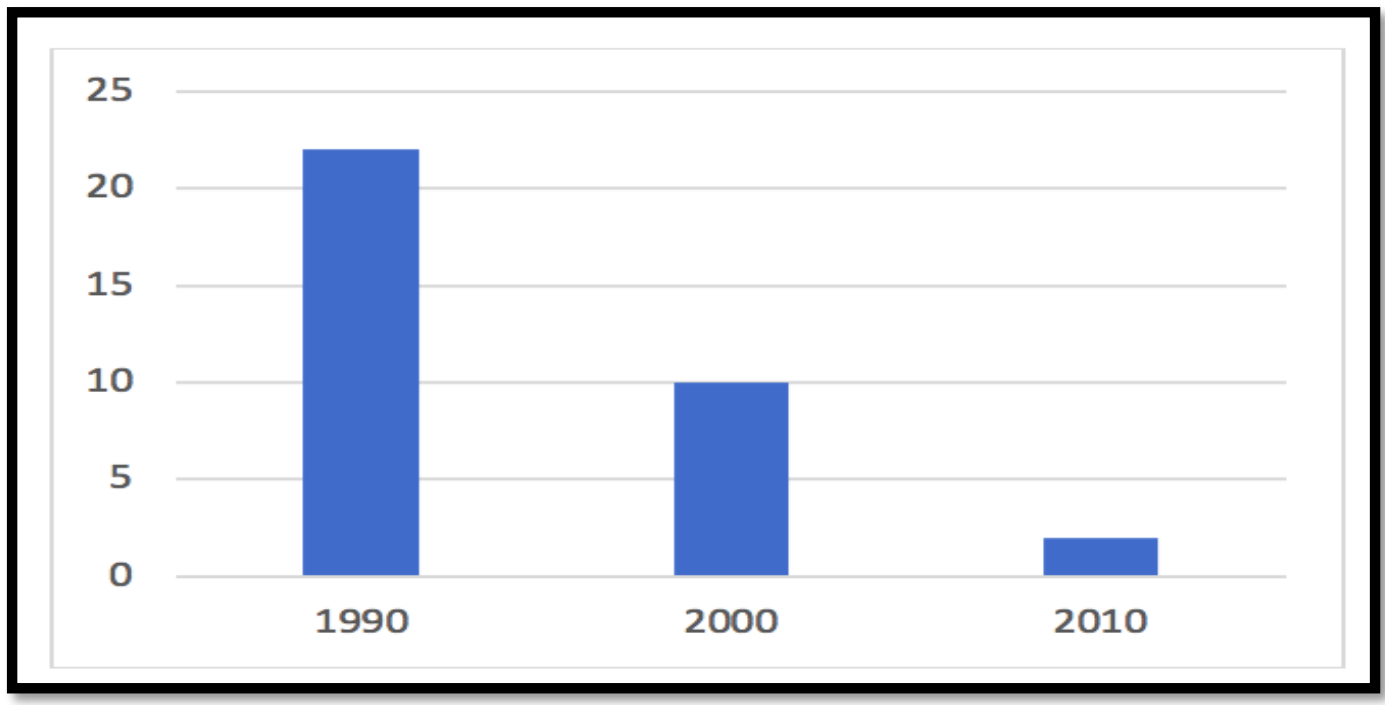

Fonte: autores, 2019.

Por seu turno, no que tange ao período da formação de professores de Geografia, esses indicadores nos permitem inferir que a maior parte deles concluiu sua graduação na década de 1990, com um número menor nas décadas de 2000-2010, e poucos professores/as formados após 2010. Segundo Costa (2012) a formação na concepção de licenciatura e bacharel, era um modelo de referência na década de 1990, organizada com três anos centrados na modalidade bacharelado e um ano voltado para a licenciatura. Este modelo de formação oferecida, previa a formação genérica e de formação geral no início do curso, possíbilitando, a partir de terminada etapa a opção para cursar bacharerlado ou licencinciatura. Neste sentido, havia a possibilidade 
de atuar nas condição de geógrafo bacharel e na docência no ensino fundamental e médio com a licenciatura.

Acerca desta formação, Costa (2012), faz uma crítica afirmando que o conhecimento específico na proposta do currículo do curso possuía maior importância em relação aos conteúdos didático-pedagógicos, atribuindo aos cursos de licenciatura um estatuto técnico/instrumental à formação, ou seja, a formação pedagógica era concebida como complementação, de caráter técnico, passível de ser efetivada com algumas pinceladas de componentes curriculares voltados para a Psicologia da Aprendizagem, a Didática, e os Fundamentos e Metodologias de Ensino, bem como o Estágio Curricular Supervisionado na Educação Básica.

Com objetivo de investigar sobre a formação da docência em Geografia, Cavalcanti (2002) realizou uma pesquisa com alguns professores/as de Geografia que tiveram a formação na modalidade licenciatura e bacharel no mesmo curso, e concluiu que grande parte dos professores/as pesquisados apresentavam possuir um saber geográfico conceitual e epistemológico mais evidente, mas com fragilidades ligadas as questões pedagógicas do contexto escolar. Isso nos leva ao entendimento de que este modelo de formação não dava conta de capacitar os/as professores/as no que tange ao saber fazer das diferentes leituras do espaço geográfico, assim como pensar a dimensão pedagógica do ensinar Geografia e a realidade da inclusão em sala de aula.

Para superar estas fragilidades dos cursos de formação inicial, nos anos de 1990 foram implantadas mudanças curriculares nos cursos de formação de professores que contribuíram para qualificar as propostas pedagógicas das licenciaturas, que resultaram na aprovação em 2002 das Resoluções do CNE/CP n. 1/2002 (BRASIL, 2002) e a Resoluções do CNE/CP n. 2/2002 (BRASIL, 2002). A primeira instaurou as Diretrizes Curriculares Nacionais para a formação de professores da Educação Básica, em nível superior, curso de licenciatura, e a segunda estabeleceu a duração e a carga horária dos cursos de licenciatura.

A implantação destas diretrizes representou um importante caminho para qualificação das propostas de formação docente mais articuladas com a Educação Básica e comprometidas com a qualidade dos processos de formação inicial e continuada de professores/as. Com isso, os cursos de licenciatura das diferentes áreas e da licenciatura em geografia, que os/as professores 
pesquisados são formados, passaram a ter os desenhos curriculares que contemplaram com mais intensidade as disciplinas pedagógicas articuladas com as disciplinas específicas do curso, com os estágios curriculares que possibilitaram a reação direta com a docência desde o início do curso. Todo este processo representou um avanço qualitativo na formação dos/das professores/as que atuam na Educação Básica e que se deparam no seu dia a dia com a realidade do cotidiano das escolas.

Após o mapeamento sobre o perfil dos participantes da pesquisa, objetivamos na sequência trazer a leitura dos dados articulados com o arcabouço teórico, considerando as falas dos professores de Geografia no que se refere ao contexto da inclusão de estudantes com deficiência na escola.

\section{Discussão e análise}

Falar sobre a formação de professores/as de Geografia em espaço/tempos declarados líquidos, híbridos e pós-modernos (BAUMAN, 2001), requer reflexão e ressignificação em relação à profissão docente, ao "ser professor/a" no interior da sociedade do conhecimento ${ }^{6}$ à inclusão de estudantes com deficiência no ensino regular. Neste contexto, Veiga-Neto (2003), sem a pretensão de esgotar as possibilidades, aponta que é preciso que os cursos de formação inicial de professores/as para Educação Básica busquem oferecer condições suficientes para que os docentes atuem de modo preparado/competente para superar os desafios e as complexidades que se apresentam no cotidiano escolar.

O autor se posiciona levando em conta a necessidade de uma formação que se expanda para além das fronteiras dos conhecimentos pedagógicos, disciplinares e das práticas de ensino. Uma formação que se ocupe em dar conta das demandas sociais, das diferenças de cada sujeito, ainda mais, que reconheça as particularidades, singularidades e especificidades de cada um/a

\footnotetext{
${ }^{6}$ Gadotti (2005) compreende a sociedade do conhecimento enquanto sociedade em rede, onde os espaços de aprendizagem ampliam-se, e tornam o mundo mais complexo. "Destacar a função social do conhecimento é importante para não cair numa análise ingênua, pois conhecimento é também poder. Falar hoje em 'sociedade em rede' e 'sociedade do conhecimento' sem fazer uma análise do seu papel político e social é escamotear a questão do conhecimento e, ao mesmo tempo, entender a sociedade como se ela fosse homogênea, não contraditória, não conflitual. Por isso, antes de mais nada, é importante nos perguntar: Para que serve o conhecimento? O que é conhecimento? Como conhecer? Conhecer em que sociedade?" (p.44).
}

Periódico Horizontes - USF - Itatiba, SP - Brasil - e020026 
durante as ações educativas. Porque negar o direito do estudante de aprender é negar a função/papel social da escola e ignorar as políticas de inclusão (VEIGA-NETO, 2003).

Neste sentido, Vilaronga e Mendes (2017), tendo como base uma abordagem social, discutem as questões escolares relativas à Educação Especial e à Educação Inclusiva, situando as metas da inclusão escolar no acesso ao conhecimento, ao direito de aprender, extrapolando uma ideia restrita de socialização do espaço da sala de aula. No entanto, a efetivação das metas citadas coloca novas exigências aos cursos de licenciatura, passando pela necessidade de reformulação do que se entende por formação de professores. As orientações estabelecidas pela LDBEN no 9394/96, em seu art.59, Inciso III, esclarece que as práticas pedagógicas e curriculares devem ser incorporadas pelos cursos de formação de professores para Educação Básica de forma imprescindível, comprometida e séria, de modo que capacite os/as professores/as para trabalharem com a Educação Inclusiva na Educação Básica (BRASIL, 1996).

Embora tenha ocorrido avanços desde a implantação da LDBEN 9394/96 e com as Diretrizes Curriculares Nacionais para a Formação de Professores da Educação Básica (DCNs) (BRASIL, 2013), os cursos de formação ainda necessitam ampliar componentes curriculares específicos e articulados aos conhecimentos relativos à Educação Inclusiva, pois este campo encontra-se em estágio embrionário, uma vez que não há expressivos diálogos, reflexões e práticas formativas que problematizem constantemente a Educação Inclusiva na Educação Básica (MAGALHÃES, 2006). Nesse contexto, Fernandes (2013) complementa dizendo que realidade formativa ainda se mostra distante do que proclamam os documentos relativos a questão, pois os cursos de licenciatura têm priorizados aspectos superficiais no que diz respeito aos estudos da Educação Inclusiva, levando assim, não só o despreparo do futuro professor/a para atuar em turmas heterogêneas, especialmente com estudantes com deficiência, mas também, a proclamação da exclusão, a qual nos posicionamos contra neste texto.

Por outro lado, Fernandes (2013) chama atenção para a necessidade dos cursos de licenciatura, neste caso especifico, o curso de Geografia impulsionar o debate sobre as especificidades da Educação Inclusiva na Educação Básica não só no sentido dos futuros professores/as conhecerem a dinâmica, as possibilidades, os limites e os desafios impostos pela realidade das escolas, mas também, para que possam qualificar suas práticas pedagógicas e que estas atendam as especificidades dos/das estudantes com deficiência no espaço escolar, porque 
o direito do acesso e de aprender juntos na Educação Básica está expresso na Lei 13.146 (BRASIL, 2015).

Acredita-se que um curso de formação inicial de licenciatura em Geografia ou de qualquer outro componente curricular, precisa contemplar em seu percurso curricular, disciplinas e/ou projetos que oportunizem os/as acadêmicos/as estudos e pesquisas que tenham como foco a inclusão no sentido amplo e, em especial, a questão da Educação Especial, pois os futuros professores/as precisam estar preparados para trabalhar com a diversidade da vida em sociedade. Defendemos, portanto, que os cursos de licenciatura em Geografia promovam discussões sobre a Educação Especial sob a perspectiva da Educação Inclusiva. Que nas disciplinas consideradas pedagógicas, os licenciandos sejam desafiados a pensar em propostas didáticas inclusivas, e que nos estágios curriculares supervisionados os futuros professores/as tenham condições de vivenciar a realidade que os espera na escola, dialogando desde o início da formação com o contexto educacional da Educação Básica em sua concretude. Com isso, os/as licenciandos estarão preparados para planejar práticas pedagógicas que valorizem as diferenças e as potencialidades de cada estudante.

É fundamental que os/as estudantes dos cursos de licenciatura tenham acesso aos conhecimentos técnicos, pedagógicos e didáticos sobre a Educação Inclusiva e as deficiências, para que possam ter uma atuação em sala de aula consciente e crítica no sentido de concretizar uma prática pedagógica que possibilite a aprendizagem dos/das estudantes, respeitando e considerando as diferenças como elementos constitutivos da relação pedagógica. De acordo com Freitas:

Mecanismos funcionais de cognição das pessoas com deficiência; consciência de suas próprias condições, conhecimentos pedagógicos e metacognitivos; Desenvolvimento da capacidade de auto-regular e de tomar consciência das etapas do processo de ensino aprendizagem; Coerência entre sua maneira de ser e ensinar, entre teoria e prática; Capacidade de ministrar aulas sobre um mesmo conteúdo curricular a alunos de diferentes níveis e compreensão e desempenho acadêmico; respeito ao ritmo de aprendizagem de cada aluno; Utilização flexível dos instrumentos de avaliação de desempenho escolar, adequando às necessidades dos alunos (2006, p.177).

Assim corrobora Magalhães (2006), dizendo que a assunção dos preceitos da Educação 
Inclusiva, no âmbito da formação docente, implica ao futuro/a professor/a de Geografia, compreender o contexto da Educação Especial, área da Educação Inclusiva, que foi implantada com objetivo de garantir a organização de recursos e serviços complementares e suplementares aos estudantes com alguma deficiência no sistema de ensino regular. Ressaltamos, nesse ínterim, que o/a professor/a tem um papel fundamental no processo de inclusão, mas existem elementos essenciais para sua efetivação com excelência, como a presença do segundo professor, espaço e tempo para planejamento de forma colaborativa (os professores pensam e planejam conjuntamente, considerando as demandas das especificidades dos seus estudantes), formação continuada, materiais didáticos e infraestrutura adequados, e condições estruturais de trabalho aos profissionais da educação.

Embora tenhamos discutido sobre alguns aspectos que consideramos importantes na formação de professores/as inerentes à modalidade da Educação Inclusiva, buscamos conhecer por intermédio da pesquisa realizada com os/as professores/as de Geografia o que pensam no que se refere à presença de estudantes com deficiência em sua prática pedagógica. $\mathrm{O}$ intuito desta investigação não é fazer juízo de valor, imputar regras e normas e tecer críticas aos professores/as, pelo contrário, é compreender as especificidades da prática, os desafios e fragilidades, relacionando com o contexto das formações e das políticas educacionais. Pontuamos que cabe aos professores/as desenvolverem seu trabalho com comprometimento, mas não desconsideramos as dimensões que perpassam o cotidiano escolar.

Ao serem questionados se foram ofertadas, durante a formação inicial, disciplinas relacionadas a Educação Inclusiva, onze professores afirmaram que não tiveram acesso às disciplinas voltadas para conhecimentos teórico-práticos sobre a Educação Inclusiva na sua graduação em Geografia. Dezenove professores/as apontaram terem frequentado disciplinas ofertadas na formação inicial, sendo três respostas associadas à Língua Brasileira de Sinais (LIBRAS) e dezesseis afirmaram que frequentaram a disciplina de Educação Especial na perspectiva da Educação Inclusiva. Em um universo de trinta e quatro professores/as participantes consideramos tímida a quantidade de apenas dezesseis cursarem a disciplina relacionada à Educação Inclusiva, sobretudo, se considerarmos que as discussões relacionadas a esse campo restritas a apenas uma disciplina, podem ser insuficientes.

Neste contexto, Skliar (2006) afirma que um dos principais problemas que impacta a 
questão da inclusão é a falta de preparo dos/as professores/as na formação inicial para lidar com as diferenças no cotidiano escolar. Embora haja um potencial formativo nos processos de formação continuada, ou seja, na prática docente, a formação inicial continua sendo elementar para esta profissão, sobretudo, no que toca a inclusão de estudantes com deficiência em turmas de ensino fundamental e médio. Acreditamos que a prática pedagógica não pode estar dissociada de conhecimentos acadêmicos e científicos, nem mesmo de uma reflexão contextual acerca da questão da inclusão, que coloque em cotejamento os saberes acadêmicos e os saberes práticos. Portanto, cabe ao processo de formação inicial, de licenciatura em Geografia, associar conhecimentos já construídos por pesquisadores da área da Educação Inclusiva às discussões e debates que se colocam diante das experiências docentes no campo da escola. A formação continuada não substitui nem dá conta de preencher lacunas deixadas pelas graduações.

Quando questionados sobre a participação em atividades e cursos de formação continuada durante o exercício da docência, muitos dos professores declararam que a escola não proporciona espaços que possibilitem aprender sobre aspectos correspondentes ao universo da inclusão, bem como, também aprender práticas que possibilitem desenvolvê-las na sala de aula com vistas à promoção da inclusão de estudantes com deficiência. Do mesmo modo que no primeiro item, o universo de pesquisados e o resultado mostra uma percepção de fragilidades nos processos de formação, no que se refere ao viés da Educação Inclusiva. Nesse contexto, o professor A chega a afirmar que "participou de uma formação continuada que tratou sobre alguns aspectos ligados ao autismo, mas as discussões foram bem genéricas, com pouca atenção aos conteúdos e a proposição de práticas pedagógicas a este perfil de estudantes".

Concordamos com Magalhães (2006) de que há poucas ações ou projetos de formação continuada que se debrucem no sentido de orientar os/as professores/as para construção e organização dos seus planejamentos que tenham uma dimensão mais próxima das representações, limitações e potencialidades dos estudantes com deficiência. Dito por outras palavras, a autora chama atenção para necessidade de a formação continuada estar articulada às demandas do contexto da Educação Inclusiva, considerando a realidade e o perfil destes estudantes. Ainda sobre a formação continuada, os dados demonstram que um professor participou de uma formação que teve como foco os estudos sobre LIBRAS, quatro sobre a Educação Inclusiva e três sobre Educação Especial. Estas formações são fundamentais para a 
qualificação do trabalho docente quando trabalhadas efetivamente nas propostas de formação continuada e ampliam as possibilidades de qualificar as práticas pedagógicas em sala de aula e o direito de aprender dos/das estudantes com deficiência.

No que concerne à importância e ao trabalho do professor de Geografia em parceria com os profissionais especializados da Educação Especial, as narrativas dos entrevistados apontaram que somente quatro professores/as possuem um contato frequente com os profissionais do Atendimento Educacional Especializado $(\mathrm{AEE})^{7}$, enquanto quinze dizem existir alguma relação. Cinco consideram a relação mediana, e seis responderam nunca ter efetivado uma proximidade. Este resultado mostra que existe um desafio a ser encarado nos espaços escolares, qual seja, o distanciamento entre os profissionais que trabalham com estudantes com deficiência.

Em concordância com Fernandes (2013), acreditamos que tanto o processo de planejamento, como o constante diálogo sobre o processo educacional, e sobre as avaliações da aprendizagem, não podem ocorrer de forma fragmentada, precisam estar articulados. Professores/as de Geografia e profissionais da AEE precisam trabalhar juntos, caminhar na mesma direção, possuir os mesmos objetivos, principalmente no que se refere à busca de construção do pensamento geográfico.

Com relação ao ser professor de Geografia de estudantes com deficiência, os/as professores/as foram convidados a relatar as principais dificuldades, desafios e limites encontrados ao organizar e desenvolver as práticas didático-pedagógicas abordando a deficiência no cotidiano escolar. A respeito das dificuldades encontradas, o professor $\mathbf{C}$ afirma que "não encontro dificuldades na prática docente. Através da perspectiva de múltiplas metodologias, sendo assim adapto as propostas individualmente, não apenas para os estudantes com deficiência, mas para todos (as)". Na mesma direção do professor $\mathbf{C}$, o professor J pontua que "a princípio não vejo problemas, mas acredito que se houvesse maior articulação com o corpo docente poderíamos atender melhor os estudantes".

A preocupação de realizar a inclusão dos/das estudantes com deficiência apontada pelos participantes coaduna com as palavras do professor B que afirma: "ser professor de um estudante com deficiência na sala de aula regular é garantir o direito dele (a) de aprender como

\footnotetext{
${ }^{7}$ O Atendimento Educacional Especializado de acordo com a Resolução n ${ }^{\circ}$ 4/2009 é considerado, prioritariamente um espaço que visa fornecer apoio, complementação de serviços educacionais inclusivos.
}

Periódico Horizontes - USF - Itatiba, SP - Brasil - e020026 
qualquer outro sujeito". Embora havendo consciência de garantir o direito de aprender e conviver a todos/as os/as estudantes, o professor B ressalta que "confesso que nos meus primeiros anos de prática tive medo e insegurança porque os conhecimentos apreendidos na faculdade foram fracos e não coadunavam com a prática do chão da escola".

De acordo com nossas análises acerca destas narrativas, podemos considerar que os/as professores/as possuem consciência e preocupação no que diz respeito a busca de caminhos e estratégias de como incluir os/as estudantes com deficiência no processo de ensino e aprendizagem de Geografia, embora a falta de estrutura pedagógica, comunicacional e relacional constituam grandes desafios para a efetivação da inclusão. Até porque promover a inclusão, de acordo com a fala do professor D "exige trabalho em equipe e metodologias diferenciadas. $E$ uma oportunidade de crescimento profissional e pessoal".

Além dos/as professores/as que procuram alternativas para incluir os/as estudantes com deficiência, a professora $\mathrm{K}$ afirma que "a minha principal angústia é responder o que é significativo para cada estudante, sobretudo nas situações em que eu ainda não aprendi a forma de entender o que eles sentem, o que pensam, se estão entendendo as atividades. Ou seja, como me comunicar". O excerto desta fala, expressa a preocupação da professora com os desafios de entender como os/as estudantes aprendem e como incluí-los nas atividades pedagógicas. Desse modo, o que fica explicito, é que durante o percurso escolar o professor/a aprende a descobrir novos caminhos por intermédio da escuta, do diálogo, da troca e do olhar comunicativo entre o cenário cultural/escolar, os/as estudantes e as práticas escolares, face a inclusão dos/das estudantes com deficiência.

Em sintonia com a professor $\mathbf{K}$, a professora $\mathbf{G}$ narra que "mesmo com minha busca individual, sinto muita dificuldade e até me sinto frustrada em não poder contribuir mais com meus estudantes que tem algum tipo de deficiência". Em relação aos seus desafios, ela destaca:

É que na rede pública estadual há poucos recursos para fazer adaptações de materiais, e tudo é feito em conjunto entre professor e segundo professor. Porém, muitas vezes, levo atividade exclusiva e ao aproximar deles (sentar com eles) percebo que há o interesse em Geografia. Precisa de um olhar diferenciado, adaptações e flexibilizações das atividades para o acompanhamento do estudante (PROFESSORA K). 
As questões tecidas pela professora $\mathbf{K}$ se aproximam com os sentidos expressos no discurso do professor $\mathbf{P}$, mas problematiza, de outra forma, as questões emblemáticas no que concerne a situação da inclusão na Educação Básica. De forma enfática, a professora $\mathbf{P}$ narra que:

A inclusão em geral fica comprometida. Penso ser uma grande responsabilidade $e$, muitas das vezes, não sei como lidar diante de algumas situações específicas. É necessário estar sempre disposto a aprender, errar, reconhecer o erro, tentar novamente, desenvolver práticas inclusivas sabendo que nós, professores, também somos aprendizes (PROFESSOR P).

Os/as professores/as entrevistados manifestam necessidades e demandas vividas em sala de aula, demonstram sentir entraves de diferentes naturezas em relação ao processo de efetivação da aprendizagem de estudantes com deficiência. Identificamos como problemáticos os seguintes elementos: conhecimento insuficiente (não saber o que fazer nem como agir), tempo de planejamento escasso, ausência de materiais adequados, excesso de estudantes em sala, ausência de diagnóstico (laudo médico). De modo geral, os/as professores/as se mostram conscientes e comprometidos com a heterogeneidade da turma. Reconhecem o direito de acesso ao conhecimento e do desenvolvimento das potencialidades dos/das estudantes, no entanto, apresentam insatisfações com as condições de trabalho ou mesmo com sua própria prática.

Algumas dessas percepções ficam manifestas nos trechos: "Muito difícil por não possuir laudo, por conta disso, não consigo incluir o estudante com deficiência. E, caso percebo e busco tratar de forma mais atenciosa o estudante, corro o risco de estar entrando em um campo que não é a minha formação" (PROFESSOR M). O sentido que o professor $\mathbf{M}$ atribui à deficiência durante o processo de ensino e aprendizagem, é bastante enraizada na matriz do modelo biomédico de que a lesão (patológico), o laudo (diagnóstico) e os métodos (técnicas, instrumentos) operam como catalizadores fundamentais para adequar de forma satisfatória as necessidades dos estudantes no cotidiano escolar.

Nessa direção, Orrú (2017, p.24) enfatiza que a escola, as práticas, o currículo e o professor se expropriam da Educação e "dão à medicina o poder de dizer quem e o que poderá aprender; quem será capaz de conviver com os outros estudantes; quem deve ter seu comportamento controlado para não atrapalhar os demais em sala de aula" e, principalmente, 
quais os estudantes que precisam de atendimento especializado dos profissionais da Educação Especial. Face a essa problemática, a autora chama atenção à necessidade de desmontar no plano das representações dos professores/as os discursos que rotineiramente são utilizados para separar, categorizar, rotular e/ou ocultar algum estudante do ensino regular baseado nos dispositivos dos critérios de diagnósticos (laudo) ou, então, "pseudalizar a inclusão a partir de propostas de integração do estudante com deficiência ora no AEE e ora em instituições especializadas" (ORRÚ, 2017, p.41).

A tentativa de descontruir os discursos de rotulações, classificações e exclusões, Diniz (2007) afirma que estes devem partir do princípio que a deficiência não é o problema da inclusão, mas, sim, que a falta de estrutura física, pedagógica, humana (social) são requisitos principais que impedem efetivamente a inclusão de todos/as que necessitam de algum apoio educacional para aprender. Além do mais, o processo de inclusão implica em compreender e conhecer os aspectos ligados às experiências sociopessoais e sociofamiliar de cada um/a dentro e fora de sala de aula, porque estas influenciam significativamente no processo de construção dos saberes geográficos. Em complemento a importância de promover a inclusão das/dos estudantes com deficiência no espaço educacional. Capellini e Mendes, afirmam que para a inclusão ter êxito no espaço educacional, é necessário:

\begin{abstract}
Ser considerado um processo e não um evento. Há que ter consideração cuidadosa sobre o que é melhor para a criança, pois nem todas as crianças beneficiam-se inicialmente de todo o tempo na classe comum; planejamento colaborativo cuidadoso, respeitando quantidade de alunos por sala de aula; e de formação em serviço para receber programas colaborativos. A inclusão realmente clama por uma mudança na filosofia e possivelmente uma reestruturação fundamental dos sistemas escolares e das escolas. Isso significa mudanças no currículo, mudanças na prática pedagógica e, especialmente, mudanças na formação dos professores (CAPELLINI; MENDES, 2007, p.123-124).
\end{abstract}

Nessa esteira, a professora $\mathbf{L}$ afirma que sua "maior frustração como professora é saber que eu não tenho tempo e estrutura para chegar a dar atenção a todos (as) os estudantes no contexto atual de precarização do trabalho docente." Esse relato coaduna com a do professor $\mathbf{H}$, que diz: "complicado pelo número excessivo de estudantes na sala de aula e de eles necessitarem de um atendimento direcionado e quase que exclusivo. Até porque se for para atender esses 
estudantes o restante 'destrói' a sala de aula".

No excerto desses dizeres, a fala do professor $\mathbf{H}$, em certa medida, é bastante provocativa para se pensar que a questão da exclusão se faz, constrói e se intensifica na sala de aula. Isso significa entender que o problema da inclusão tem existência no interior dos discursos dos/as professores/as devido excesso de estudantes numa mesma turma. Promover a inclusão, de acordo com Orrú (2017, p.45) "pressupõe fazer com o outro, aprender com outro e não sozinho, segregado, marginalizado" e ainda mais, isolado em espaços especializados Acreditamos que estudantes com deficiência e sem deficiência podem aprender, estudar e realizar atividades conjuntamente, em um processo dialógico mais autônomo e horizontal, menos verticalizado pela hierarquia da sala de aula.

Neste sentido, o panorama explicitado pelas narrativas dos/das professores/as de Geografia, revela a preocupação e o comprometimento com a aprendizagem de todos/as os estudantes em suas diferenças, ressaltando inclusive a prática de adaptações de atividades, tarefas e provas de acordo com as particularidades de cada estudante. Percebemos que há, na totalidade do universo pesquisado, consciência do direito de aprender de todos/as os sujeitos presentes na escola. No entanto, os/as professores/as apresentam muitas insatisfações com os processos de inclusão nas aulas de Geografia, em alguns casos, por falta de conhecimento, outros, por falta de condições materiais, em outros, pela necessidade de articulação entre o conhecimento acadêmico e a formação continuada.

\section{Tecendo algumas reflexões}

Este texto objetivou pensar e apresentar uma pesquisa realizada com trinta e quatro professores/as de Geografia sobre suas percepções, concepções e saberes acerca da inclusão de estudantes com deficiência em sala de aula. Questionamos sobre o acesso às disciplinas relacionadas à inclusão na formação inicial, continuada, e sobre a relação com profissionais especializados em educação especial, e com os/as estudantes com deficiência nas práticas pedagógicas. Esta investigação surge com o intuito de conhecer a realidade destes professores/as através das suas narrativas que revelam a preocupação com uma educação para todos/as com qualidade, respeito às diferenças e a valorização da diversidade. 
As narrativas dos/as professores/as indicam preocupação e consciência com o direito de aprender desses sujeitos, e com a importância dos conhecimentos e esferas acadêmicas que dizem respeito ao campo da Educação Inclusiva. Sinalizam, no entanto, algumas angústias que são entreves e obstáculos no processo pedagógico de inclusão, como fragilidades nas licenciaturas em Geografia com relação a oferta de disciplinas e/ou projetos voltados a Educação Inclusiva, formações continuadas oferecidas pelas instituições escolares com foco nesta área, poucos investimentos na educação pública, precarização do trabalho docente e ausência de laudos e diagnósticos dos estudantes com deficiência.

Concordamos que a precarização do trabalho docente, os baixos investimentos na Educação Básica pública, as fragilidades nos cursos de graduação para formação de professores/as e formação continuada se constituem como entraves para implantação de práticas inclusivas em sala de aula. No entanto, este trabalho não visa reafirmar o que tantos pesquisadores e cientistas da educação já sinalizam, mas problematizar as questões que envolvem a formação e o cotidiano dos/das professores/as que trabalham com estudantes com deficiência em sala de aula.

Ao mesmo tempo que a pesquisa nos mostrou que a formação inicial e continuada são espaços por excelência que preparam os/as professores/as para a docência e o planejamento de práticas pedagógicas para o trabalho em sala de aula, ela também nos mostrou, a necessidade de superar algumas fragilidades deste processo ligadas aos conhecimentos genéricos relacionados à Educação Inclusiva, e por conta disso, os/as professores/as sentem insegurança e sem a devida qualificação para trabalhar com as/os estudantes com deficiência e promover modelos escolares inclusivos.

A partir das reflexões aqui apresentadas, entendemos que é preciso estar atento as demandas que são postas à escola no que se refere à diversidade e a inclusão, particularmente dos/das estudantes com deficiência, que necessitam ter garantidos os seus direitos de aprendizagem com práticas pedagógicas inclusivas e a devida flexibilização curricular que atendam às suas especificidades.

\section{Referências}


BAUMAN, Z. Modernidade líquida. Trad. Plínio Dentzien. Rio de Janeiro: Jorge Zahar, 2001.

BRASIL. Ministério da Educação. Lei $n$ o 9.349, de 20 de dezembro de 1996. Lei de Diretrizes e Bases da Educação Nacional. Brasília, 1996. Disponível em: http://www.planalto.gov.br/ccivil_03/leis//9394.htm. Acesso em: 19 mar. 2019.

BRASIL. Resolução CNE/CP no 01/2002, de 18 de fevereiro de 2002. Institui Diretrizes Curriculares Nacionais para a formação de professores da educação básica, em nível superior, em cursos de licenciatura, de graduação plena. Brasília, 2002. Disponível em: http://portal.mec.gov.br/cne/arquivos/pdf/rcp01_02.pdf. Acesso em: 19 mar. 2019.

BRASIL. Resolução CNE/CP no 02/2002, de 19 de fevereiro de 2002. Institui a duração e a carga horária dos cursos de licenciatura, de graduação plena, de formação de professores da educação básica em nível superior. Brasília, 2002. Disponível em:

http://portal.mec.gov.br/cne/arquivos/pdf/CP022002.pdf. Acesso em: 19 mar. 2019.

BRASIL. Política nacional de educação especial numa perspectiva da educação inclusiva. Brasília, 2008. Disponível em: http://portal.mec.gov.br/arquivos/pdf/politicaeducespecial.pdf. Acesso em: 19 mar. 2019.

BRASIL. Resolução no 4, de 2 de outubro de 2009. Diário Oficial da União: Brasília, 24 de outubro de 2009 , seção 1, p.17.

BRASIL. Ministério da Educação. Secretaria de Educação Básica. Diretoria de Currículos e Educação Integral. Diretrizes Curriculares Nacionais Gerais da Educação Básica. Brasília: MEC, SEB, DICEI, 2013. Disponível em: http://portal.mec.gov.br/docman/julho-2013-pdf/13677diretrizes-educacao-basica-2013-pdf/file. Acesso em: 19 mar. 2019.

BRASIL. Lei no 13.146, de 6 de julho de 2015. Lei brasileira de inclusão da pessoa com deficiência. Brasília, 2015. Disponível em http://www.planalto.gov.br/ccivil_03/_ato20152018/2015/lei//13146.htm. Acesso em: 19 mar. 2019.

CAPELLINI, V. L. M. F; MENDES, E. G. O ensino colaborativo favorecendo o desenvolvimento profissional para a inclusão escolar. Educere et Educare, Cascavel, v.2, n.4, p.113-128, jul./dez. 2007.

CAVALCANTI, L. S. Geografia e práticas de ensino. Goiânia: Alternativa, 2002.

COSTA, F. F. Formação inicial de professores: novas políticas para velhas práticas. In: SEMINÁRIO DE PESQUISA EM EDUCAÇÃO DA REGIÃO SUL (ANPED SUL), 9., 2012, Caxias do Sul. Anais [...]. Caxias do Sul: Campus UCS, 2012. p.1-17.

DINIZ, D. O que é deficiência. São Paulo: Brasiliense, 2007.

FERNANDES, S. Fundamentos para educação especial. Curitiba: Intersaberes, 2013. 
FREITAS, S. N. A formação de professores na educação inclusiva: construindo a base de todo o processo. In: RODRIGUES. D. (org.). Inclusão e educação: doze olhares sobre a educação inclusiva. São Paulo: Summus, 2006.

GADOTTI, M. Informação, conhecimento e sociedade em rede: que potencialidades? Educação, Sociedade \& Culturas, v.23, p.43-57, jan./dez. 2005.

GONÇALVES, E. P.Conversas sobre iniciação à pesquisa científica. Campinas: Alínea, 2007.

MAGALHÃES, R. C. B. P. Processos formativos e saberes docentes em tempos de inclusão: apontamentos a partir de contribuições da educação especial. In: ENCONTRO NACIONAL DE DIDÁTICA E PRÁTICAS DE ENSINO, Anais [...]. Recife: EDIPE, 2006. p. 1-18.

ORRÚ, S. E. O re-inventar da inclusão: os desafios da diferença no processo de ensinar e aprender. Petropolis: Vozes, 2017.

SKLIAR, C. A inclusão que é "nossa" e a diferença que é do "outro". In: RODRIGUES, D. (org.) Inclusão e educação: doze olhares sobre a educação inclusiva. São Paulo: Summus, 2006. p. 114.

VEIGA-NETO, A. Os estudos culturais e a formação docente. In: QUADROS, C.; AZAMBUJA, G. (orgs.). Saberes e dizeres sobre a formação de professores na Unifra. Santa Maria: Centro Universitário Franciscano, 2003.

VILARONGA, C. A. R.; MENDES, E. G. Formação de professores como estratégia para realização do coensino. Diálogos e Perspectivas em Educação Especial, v.4, p.19-31, 2017.

Recebido em agosto 2019.

Aprovado em abril 2020. 